\title{
LEITURA DE UM TEXTO DE DIVULGAC̣ÃO CIENTÍFICA EM UMA DISCIPLINA DE FÍSICA BÁSICA NA EDUCAÇ̃̃O SUPERIOR
}

\author{
Marcelo Zanotello* \\ Maria José Pereira Monteiro de Almeida**
}

RESUMO: A inserção de atividades que estimulem a mediação cultural em aulas das disciplinas científicas, articuladas com a abordagem didática tradicional, pode contribuir para uma ampliação dos objetivos do ensino de ciências. A leitura de textos de divulgação científica é uma estratégia viável para desenvolver mediações em ambientes formais de ensino. Neste trabalho, analisamos a produção de sentidos por alunos do primeiro ano de um curso superior, a partir da leitura de um texto sobre a evolução da termodinâmica. Apoiando-nos no referencial da análise de discurso, em uma de suas vertentes francesas, observamos deslizamentos nas concepções dos estudantes e indícios da constituição de saberes novos, a partir do registro por escrito, de suas respostas, a um questionário sobre o texto. Os relatos dos alunos revelam uma ampla variedade de colocações que subsidiam a atuação docente.

Palavras-chave: Leitura. Divulgação Científica. Produção de sentidos. Termodinâmica.

\section{READING OF A SCIENTIFIC DIVULGATION TEXT IN A UNIVERSITY CLASS OF GENERAL PHYSICS}

ABSTRACT: The inclusion of activities that encourage cultural mediation in classes of scientific disciplines, articulated with the traditional didactic approach, can contribute to extend the goals of scientific education. The reading of scientific divulgation texts is a viable strategy to develop mediations in formal educational environments. In this paper, we analyse the production of meanings by first-year students in a university course by reading of a text about thermodynamics' evolution. Using French Discourse Analysis, we identified slips in students' conceptions and indications of formation of news representations, analyzing written registers of students' answers to a questionnaire about the text. The collected reports reveal a wide variety of statements that considerably support the teachers' role.

Keywords: Reading, scientific divulgation, production of meanings, thermodynamics. 


\section{INTRODUC̣ÃO}

Esta pesquisa empírica se insere em um contexto que procura identificar elementos para reflexão sobre algumas questões referentes ao ensino de ciências, mais especificamente da Física, que consideramos importantes para subsidiar a atuação docente em qualquer nível de ensino:

Como orientar o ensino para abordagens culturalmente mais ricas? Como contribuir para a compreensão da linguagem formal da física? Como se processa a internalização de conteúdos específicos da ciência com a mediação da leitura? Como o estudo da ciência pode contribuir para o hábito de leitura de textos científicos ou de outra natureza? Como as representações de alunos e professores interferem na mediação do conhecimento científico e nos modos de ler sobre ciência? (ALMEIDA, 1998, p.54)

De acordo com uma concepção de ciência que entende essa instituição como integrante do arcabouço cultural da humanidade (ZANETIC, 2005), os objetivos de seu ensino se ampliam, sugerindo que ele não fique restrito ao formalismo constante nos manuais didáticos:

Numa perspectiva de mediação cultural, as finalidades para se ensinar ciência podem assumir um espectro bastante abrangente, podendo-se esperar desse ensino que ele possibilite ao estudante, entre outros objetivos: a internalização de conceitos e leis previamente selecionados; o reconhecimento das condições sociais em que determinadas leis da natureza e certos conceitos foram produzidos, bem como o entendimento de suas influências sobre a sociedade; a compreensão de modos de produção da ciência; a possibilidade de crítica em relação a aplicações e implicações sociais da instituição científica; a aquisição de habilidades e atitudes pertinentes ao fazer científico; o incremento da auto-estima pela inserção em questões próprias do seu tempo. Evidentemente, esses e outros possíveis objetivos não são mutuamente excludentes (ALMEIDA, 2004, p.96).

A leitura de gêneros textuais distintos em relação aos livros didáticos tradicionais pode ser viabilizada quando se considera um panorama de diversificação de estratégias para as aulas das disciplinas científicas. Um texto escrito em uma linguagem razoavelmente próxima à do estudante, como é o caso da maioria dos que se destinam à divulgação científica, que seja trabalhado em atividades de leitura como introdução a determinados temas, pode contribuir para uma prática que busque a referida ampliação nos objetivos do ensino das ciências.

Em muitas ocasiões, temas como a história da ciência, as relações entre ciência, sociedade e o desenvolvimento tecnológico, seus modos de produção e até mesmo uma análise mais cuidadosa de certos conceitos não são tratados de modo conveniente nas disciplinas científicas introdutórias no ensino superior. Além disso, não são abordados nos livros didáticos usuais de modo satisfatório, sendo buscados por parcela geralmente minoritária dos alunos em leituras complementares, desarticuladas do trabalho em aula. A utilização de textos de divulgação científica que discutam tais temas configura-se como uma possibilidade de trazê-los para as aulas e organizar as formas de explorá-los. Nesse sentido, o uso de textos de 
divulgação científica, segundo Salém e Kawamura (1996), pode contribuir para enriquecer o ensino, "localizando o conteúdo em um contexto mais abrangente, motivando e mesmo aprofundando determinados assuntos". Silva e Kawamura (2001) afirmam que, na maioria dos casos, o material de divulgação apresenta-se mais "instigante" que os manuais didáticos, revelando potencial para uso como recurso alternativo. Geralmente, tais textos são atrativos e motivadores para leitura, uma vez que procuram apresentar os conceitos de forma acessível a um público leigo. Seus autores procuram evitar, no caso da Física, a linguagem formal matemática, constitutiva dessa ciência, já que os textos de divulgação não são direcionados para os especialistas de determinada área do conhecimento. Martins, Nascimento e Abreu (2004) indicam que:

[...] a contribuição da divulgação científica para o ensino pode se efetivar, entre outras formas, a partir dos potenciais benefícios advindos do contato com diferentes formas de dizer e argumentar contidas nesses textos [...] (MARTINS, NASCIMENTO E ABREU, 2004, p.97).

Algumas experiências têm sido relatadas a respeito da utilização de textos de divulgação em aulas de disciplinas científicas. Pinto (2007) discute as potencialidades da divulgação científica como gênero literário para o ensino de ciências. Strack, Loguércio e Del Pino (2009) investigam as percepções de professores de Química do ensino superior sobre a inserção de livros de divulgação científica como instrumento pedagógico na prática docente. Nascimento e Cassiani (2009) relatam experiências de licenciandos em Ciências Biológicas que empregaram textos de divulgação em atividades de estágio supervisionado, analisando suas possibilidades de utilização no ambiente escolar. Dias e Almeida (2009) trabalham os possíveis usos de textos de divulgação científica das revistas Ciência Hoje e Pesquisa Fapesp, relacionando-os com características inerentes ao discurso do jornalismo científico presentes nessas publicações. Um aspecto importante, destacado nas pesquisas citadas, é a necessidade frequente de algum tipo de adaptação desses textos para que eles possam ser aplicados em atividades didáticas, pois, originalmente, não foram elaborados com esse propósito. Isso é possível na medida em que a divulgação científica está entre os gêneros discursivos que têm como "característica inerente uma maleabilidade que lhe confere a capacidade de adaptação e reformulação para atender novos propósitos e contextos" (MARTINS, NASCIMENTO E ABREU, 2004, p. 98). Embora Nascimento (2005) alerte para a possibilidade de um texto de divulgação gerar "obstáculos pedagógicos" quando aplicado no ambiente formal de ensino, acreditamos que a mediação do professor junto aos alunos pode contribuir para que ele funcione como aliado à aprendizagem de determinados conteúdos e como elemento motivador para posteriores desenvolvimentos, em um processo gradativo de formação de uma visão mais ampla sobre a ciência.

O conjunto de pesquisas aqui citadas possibilita visualizar um amplo espectro de alternativas para o uso da divulgação científica no ensino formal. Entretanto, consideramos serem necessárias mais investigações sobre situações 
em que a leitura de textos dessa natureza ocorra de modo articulado com as aulas de disciplinas científicas. Assim, definimos como objetivo deste trabalho a busca de indícios que permitam identificar de que maneiras um texto de divulgação científica pode ser utilizado em aulas de Física, como recurso didático que contribua para a mediação e a produção do discurso escolar relativo ao conhecimento científico, no início do curso superior. As questões de estudo que orientaram esta pesquisa foram as seguintes:

Como as atividades de leitura de determinado texto de divulgação podem se transformar em elementos motivadores para o desenvolvimento de temas nas aulas? Que novas concepções sobre o tema tratado no texto podem ser constituídas, a partir da leitura e da mediação do professor? Essas leituras subsidiariam uma reflexão acerca da evolução do conhecimento científico em determinada área, dadas as relações com o contexto sócio-histórico da época em que tal conhecimento foi construído? Quais os limites desse tipo de prática quando realizada com alunos que cursam as disciplinas iniciais do curso de Física no ensino superior?

Analisamos a produção de estudantes do primeiro ano de um curso superior em Ciência e Tecnologia, em uma universidade federal, no Estado de São Paulo, a partir da leitura de um texto de divulgação científica cujo tema é a evolução da termodinâmica. A análise qualitativa se baseou nos registros por escrito das respostas dos alunos a um questionário proposto juntamente com a solicitação de leitura do texto.

\section{PRESSUPOSTOS TEÓRICOS}

Para a aprendizagem em ciências, Bachelard pressupõe a ocorrência de rupturas (BACHELARD, 1996; LOPES, 1993) com o senso comum que alterem as concepções dos estudantes e instaurem novas interpretações, condizentes com o conhecimento científico. Tal conhecimento é constituído por uma linguagem especializada, por vezes revelando-se completamente nova para o estudante. $\mathrm{Na}$ formação acadêmica, é imperativo que os alunos se apropriem da linguagem formal constitutiva de suas áreas, devendo dominar toda uma gama de novos conceitos, terminologias e procedimentos. Entretanto, mesmo após completarem suas formações acadêmicas, as pessoas continuam a manifestar, em certas ocasiões, noções de senso comum, evidenciando que a referida ruptura não é total ou absoluta. Mas, ainda que se admita a possibilidade de uma coexistência entre diversas concepções relativas às ciências, um indicativo da ocorrência de uma aprendizagem pode ser a presença, nos discursos do indivíduo, de um conhecimento mais próximo do formal.

No referencial da Análise de Discurso (AD), em sua vertente iniciada na França por Michel Pechêux, a leitura é entendida como um processo que, segundo Almeida e Ricon (1993), permite o afloramento de conhecimentos anteriores. $\mathrm{Na}$ leitura, o indivíduo pode notar, ampliar, aprofundar, analisar criticamente e romper 
com alguns desses conhecimentos, pois é por meio da relação que se fará entre conhecimentos anteriores e aqueles a serem interpretados no texto que se inicia a constituição dos sentidos. Esse processo pode ser exemplificado pela concepção adotada por Smith (1999), segundo a qual fazer perguntas ao texto escrito possibilita o exercício da interpretação que caracteriza, em essência, o ato de ler. O funcionamento da leitura não se dá por mera assimilação de conteúdos, supostamente contidos no texto. Não se trata apenas de um processo de decodificação, mas de atribuição e construção de sentidos que não estão, necessariamente, no texto, constituindo-se em um ato interpretativo (ZANON, ALMEIDA, QUEIROZ, 2007). A $\mathrm{AD}$ considera que o sentido não está fixado a priori, tampouco pode ser qualquer um: há uma determinação histórica do sentido, de modo que o discurso é definido pelas formações imaginárias que se constituem a partir das relações sociais do indivíduo e cuja materialidade é linguística (ORLANDI, 1994, 2007).

Nesse enfoque, a linguagem não é transparente e o sujeito que lê constrói suas interpretações em determinadas condições de produção, apoiado na sua memória discursiva. A relação entre o mundo e a linguagem se dá através da ideologia, entendida como o imaginário social que medeia as relações do sujeito com suas condições de existência. Daí a importância do conceito de interdiscurso, no qual o ato de ler é cumulativo: cada leitura baseia-se no que a pessoa leu ou conheceu anteriormente, ou seja, o já dito sustenta a possibilidade do dizer. Assim, na autoria do discurso, na produção de um sentido, o indivíduo se liga à sua história para formular um enunciado, instaurando um lugar de interpretação e utilizando algum tipo de repetição.

Dentre as possibilidades de repetição, destacam-se: a repetição empírica, que consiste em simples exercício mnemônico; a repetição formal, associada à técnica de produção de frases; e a repetição histórica, que seria propriamente a memória constitutiva dos sentidos. Assumir tal suporte teórico implica em adotar uma concepção de aprendizagem na qual as "possibilidades da escola, em qualquer nível de ensino, estão na criação de condições para que o aluno trabalhe sua relação com suas filiações de sentido, com a memória do dizer" (ALMEIDA, 2004). Em suma, estabelecer condições para que o estudante passe da repetição empírica para a histórica:

[...] na repetição histórica teríamos um aluno com um real trabalho da memória: ele inscreveria assim o dizer em seu saber discursivo o que lhe permitiria não só repetir, mas ao fazê-lo, produzir deslizamentos, efeitos de deriva no que diz. Por isso haveria aí sempre a possibilidade de serem produzidos outros dizeres a partir daqueles. Esse seria o "ideal" da aprendizagem: levar o aluno a passar da repetição empírica à histórica, com passagem obrigatória pela formal já que para que haja sentido é preciso que a língua se inscreva na história (ORLANDI, 1998, p.14).

Os deslizamentos, conforme entendidos na AD, poderiam ser identificados nos discursos dos alunos em determinadas condições de produção, evidenciando rupturas com seus saberes anteriores e revelando indícios da construção de um novo saber. Amparados nesse referencial, salientamos que equívocos podem ocorrer 
quando se propõe uma atividade de leitura com textos de gênero distinto ao do livro didático em aulas de ciências. Dentre eles, citamos a crença de que a leitura destina-se apenas a buscar informações no texto, atribuindo-se um sentido único e verdadeiro. Isto faria com que ele fosse lido como frequentemente é proposta a leitura de livros didáticos: com a finalidade de responder questões fechadas, previamente formuladas pelo professor. Uma alternativa para se tentar evitar tal equívoco consiste na proposição de questões abertas abrangendo os temas tratados no texto. Esse tipo de pergunta pode contribuir para que o aluno se envolva na leitura e se posicione, constituindo-se em um caminho que estimule o diálogo do leitor com o conhecimento veiculado pelo texto.

\section{ASPECTOS METODOLÓGICOS}

A atividade foi proposta para 90 alunos matriculados em uma das turmas da disciplina Fenômenos Térmicos no ano de 2008, em uma Universidade Federal no Estado de São Paulo. Os alunos estavam cursando o segundo quadrimestre do primeiro ano do curso de Bacharelado em Ciência e Tecnologia. Tal curso é integrado por estudantes com interesses em áreas variadas, que poderão cursar, posteriormente, na própria universidade, bacharelados ou licenciaturas em Física, Matemática, Química e Biologia; bacharelados em Ciência da Computação, Neurociências ou, ainda, uma das oito modalidades de engenharia oferecidas. Na ocasião, o primeiro autor deste trabalho era o professor regular da turma. A bibliografia básica consistia em um livro didático tradicional de Física para o ensino superior (HALLIDAY, RESNICK, WALKER, 2006), de modo que a leitura do texto de divulgação científica se constituiu em um diferencial.

A escolha do texto de divulgação é uma questão que envolve uma avaliação criteriosa, que deve considerar a adequação do texto em relação aos conteúdos apresentados e ao perfil dos potenciais leitores. Alguma eventual simplificação que seja feita pode servir como elemento que estimule diálogos a respeito do conteúdo do texto e não invalida, a priori, seu potencial de utilização em sala de aula com a mediação do professor. O texto escolhido para a realização da atividade corresponde a um capítulo do livro "A Dança do Universo" (GLEISER, 1997). Nessa parte da obra, Gleiser narra sobre aspectos relacionados ao desenvolvimento da termodinâmica e da teoria cinética dos gases, sem utilizar o formalismo matemático e colocando pequenos parágrafos retirados dos originais de alguns cientistas. Como se pretendia focar o trabalho com os alunos na questão sobre a natureza física do calor, foi realizado um recorte no capítulo, de modo que foram suprimidos os parágrafos que tratavam da entropia e da segunda lei da termodinâmica. Consideramos que isso foi feito sem comprometer a continuidade do texto resultante da seleção.

Ao se referir ao livro "A Dança do Universo", Martins (1998) acusa alguns equívocos nele contidos. Dentre os que correspondem a trechos que estão presentes 
no texto proposto para leitura dos estudantes, Martins aponta os seguintes: na frase: "Sabemos que o calor sempre flui de objetos quentes para objetos frios", ele frisa que o calor pode fluir de objetos frios para objetos quentes, como nos refrigeradores, e que a frase se corrigiria com a colocação de que "(...) o calor sempre flui espontaneamente de objetos quentes para objetos frios”; na afirmação: “(...) a pressão de um gás é proporcional ao produto da densidade de moléculas por sua velocidade média”, o correto seria dizer que a pressão não é proporcional à velocidade média e sim à média dos quadrados das velocidades moleculares. Apesar de pertinentes, em nossa perspectiva tais constatações não desqualificam o texto para ser trabalhado na atividade de leitura sugerida. Esses pontos são tratados de maneira detalhada e rigorosa no decorrer da disciplina e podem servir como objeto de mediação com os alunos.

Com a intenção de que a atividade fosse realizada antes da discussão formal do conceito de calor no curso, o texto e as questões foram disponibilizados no primeiro dia de aula e os estudantes dispuseram de uma semana para realizar a tarefa individualmente. O questionário continha as seguintes instruções e perguntas.

\section{Antes de ler o texto:}

1 - Como você explicaria para alguém o que é o calor? Elabore um pequeno texto.

Após a leitura:

2- Quais suas dúvidas?

3- Como você acha que se dá a produção de novos conceitos e a evolução do conbecimento científico?

4- Você modificaria ou acrescentaria algo na resposta dada à primeira pergunta? Em caso afirmativo, o quê?

Se quiser, faça alguns comentários sobre o texto e/ ou a atividade desenvolvida.

$\mathrm{Na}$ data estipulada, 71 estudantes entregaram suas respostas. Foi enfatizado que não seriam atribuídas notas para o trabalho, que o objetivo não era discriminar respostas certas e erradas e que a realização da tarefa contribuiria para a constituição do conceito final na disciplina. A proposição de questões abertas evidencia o caráter exploratório, qualitativo da pesquisa, em que a maior preocupação não é verificar a fixação de conteúdos, mas o funcionamento da leitura do texto de divulgação, usado como introdução à disciplina.

\section{ANÁLISE DA PRODUC̣ÃO DOS ESTUDANTES}

\section{a. Concepções sobre 0 calor}

As respostas dadas à primeira questão permitem identificar algumas noções dos alunos sobre o tema calor, antes do contato com a disciplina no ensino superior. Obviamente, não há garantias de que a instrução que solicitava que a questão fosse respondida antes da leitura do texto tenha sido seguida. É possível 
que eles tenham recorrido ao próprio texto, ou a outras fontes, para responder. Mas, o fato de se ter enfatizado que as respostas não seriam corrigidas atribuindo-se certo ou errado pode ter contribuído para que vários deles seguissem a instrução e respondessem mais livremente. Notamos certas noções que, aparentemente, não se relacionam diretamente à leitura do texto. Tais noções podem ter origens diversas. Provavelmente, algumas foram assimiladas no Ensino Médio e associam-se ao uso de definições semelhantes às encontradas em livros didáticos e apostilas, normalmente adotados naquele nível de ensino. Outras advêm de impressões desenvolvidas fora do ambiente escolar, por exemplo, através de leituras de livros, reportagens de jornais e revistas, documentários de televisão, sites da internet e, até mesmo, a partir de sensações fisiológicas. Os exemplos de respostas transcritas ilustram esses aspectos. Os nomes dos alunos citados são fictícios e suas grafias originais são mantidas.

Marta enuncia uma definição para o conceito de calor similar às encontradas em livros didáticos. Em seu exemplo, observa-se a tentativa de associação entre a percepção fisiológica de "quente e frio" com a transferência de energia entre a mão e uma mesa de alumínio.

Calor é uma forma de energia em trânsito, transferida dos corpos de maior temperatura para os corpos de menor temperatura. Ex: ao encostarmos a mão em uma mesa de alumínio que se encontra na temperatura ambiente (aprox. 25oC), a mão (considerando a temperatura corporal entre $36 \mathrm{oC}$ e $37 \mathrm{oC}$ ) transfere energia na forma de calor para a mesa de alumínio, passando-nos a sensação de que está muito fria (Marta).

Ana e Maria se detêm no aspecto fisiológico, sendo que Maria enfatiza a importância da utilização do calor para o homem primitivo.

[...] entendo como calor a sensação que se tem num ambiente aquecido ou na presença de um objeto quente. (Ana)

O calor, quando sentido, gera uma sensação de aquecimento, está presente no fogo, na luz do sol; quando atinge altas temperaturas, pode machucar, causando queimaduras. Ele é e sempre foi fundamental para a sobrevivência da humanidade; com ele o homem das cavernas pôde aquecer a comida (caça), afastar os predadores, gerar iluminação e ajudou a aquecer durante o inverno e, assim, sobreviver. (Maria)

João acrescenta uma citação sobre a geração de energia elétrica em uma usina, a partir do calor.

[...] É uma energia facilmente dissipada e é muito usada na produção de energia elétrica, onde o calor gerado pela queima de combustíveis fósseis movimenta as turbinas. Essas, juntamente com outros processos, geram corrente elétrica. (João)

Admitindo que os alunos tenham estudado algo sobre calor no Ensino Médio, evidencia-se, em seus relatos, a coexistência de saberes associados à ciência 
com elementos de senso comum. Sandra associa o calor a uma modalidade de energia à qual se aplica um princípio de conservação, destacando que um corpo não pode criar calor, mas somente recebê-lo ou transmiti-lo.

Explicaria que calor é energia, que se conserva, ou seja, que um corpo não pode criar calor e sim passá-lo e recebê-lo, explicando o princípio de conservação da energia. (Sandra)

Ângela e Luiz enfatizam a ideia de que corpos com diferentes temperaturas, quando colocados em contato, alcançam o equilíbrio térmico, sendo que Ângela cita a expressão "grau de agitação", provavelmente esboçando uma relação com a constituição molecular da matéria, mas sem explicitar seu entendimento sobre essa expressão.

Os corpos em contato buscam o mesmo grau de agitação, assim um tende a liberar fluxo de calor para o outro. Está ligado à grandeza temperatura. (Ângela)

Calor seria a interação entre corpos que trocam energia, que resulta no equilíbrio de temperatura. (Luiz)

Calor parece ser algo inerente de certo material ou substância. É relacionado à temperatura de um corpo. Também relacionado com o estado físico das substâncias. Quando se menciona calor, no mesmo instante a ideia de temperatura e mudanças de estado físico nos vem à cabeça. (Rodrigo)

Ao afirmar que "calor parece ser algo inerente de certo material ou substância”, Rodrigo nos fornece evidências de um imaginário que associa calor a algo material, semelhante ao que ocorreu no princípio do desenvolvimento da termodinâmica com a teoria do calórico.

[...] Em qualquer trabalho mecânico realizado, existe sempre a dissipação de calor para o ambiente, ou seja, nenhuma máquina apresenta $100 \%$ de eficiência. Dessa forma, o calor está relacionado com o movimento. (Flávio)

Flávio foca sua resposta na conversão da energia térmica em mecânica. Em alguns casos, há uma confusão entre os conceitos de temperatura e calor, como no caso de Roberto:

O calor de um corpo é definido como o estado de agitação das moléculas que o compõe, sendo medido através de unidades de temperatura Celsius, Fahrenheit e Kelvin. (Roberto)

Rogério apresentou uma resposta altamente elaborada, tanto do ponto de vista conceitual em Física, como na forma de expressão escrita:

Este é um conceito que provoca muitas confusões. É comum ouvirmos que calor é aquela sensação que sentimos num dia quente, ou que calor é sinônimo de temperatura. Mas essas ideias são equivocadas, embora o calor esteja ligado a essas coisas. Em um corpo, 
todas as partículas possuem determinados movimentos (vibração, rotação, ...) que conferem a ela uma determinada energia cinética. Entretanto, nesse corpo, todas as partículas não possuem necessariamente a mesma energia cinética. Assim sendo, não conseguimos obter diretamente a energia cinética dessas partículas, mas, através da grandeza temperatura, podemos dimensionar a energia cinética média de todas as partículas desse corpo. Quando dois corpos estão a temperaturas diferentes, a energia cinética média de suas partículas também são diferentes. Se esses corpos entrarem em contato, o movimento das partículas de um corpo será de algum modo transferido às partículas do outro corpo até que os movimentos das partículas dos dois corpos sejam tais que a energia cinética média de suas partículas se equiparem, ou seja, até que esses corpos atinjam a mesma temperatura, atinjam o equilíbrio térmico. Mas como o movimento das partículas de um corpo pode ser transferido às partículas de outro corpo? Simplesmente transferindo energia do movimento das partículas de um corpo às partículas de outro corpo. A essa energia de movimento das partículas que foi transferida de um corpo para outro damos o nome de calor. (Rogério)

Apesar da maioria das respostas terem sido curtas, sem maiores tentativas de elaboração, a análise dos relatos mostra uma flagrante heterogeneidade na turma, em termos dos conhecimentos por eles trazidos e que são condicionados por suas histórias individuais. A interpretação e a atribuição de sentidos são influenciadas por uma memória discursiva, conforme destacado pela AD. O conhecimento dessa variedade de concepções que os alunos trazem pode se tornar um instrumento pedagógico útil para auxiliar a prática do professor. Nas respostas a essa primeira questão, não identificamos cópias de trechos do texto de divulgação.

\section{b. As dúvidas}

Na segunda questão, foi solicitado aos estudantes que expressassem suas dúvidas em relação ao texto. A mediação dialógica, que pode advir do conhecimento, por parte do docente, das dúvidas de seus alunos, pode fazer com que novas concepções se constituam e que determinados conceitos sejam compreendidos. Dos 71 trabalhos analisados, 28 não apontaram dúvidas. Nos demais, uma série de questionamentos foram colocados a respeito de diversos aspectos do texto, por exemplo, sobre os conceitos de calor e energia:

Quais as diferenças entre tantas energias? (Muriel)

Como é medido o calor? Como outros tipos de energia se transformam em calor? (Vicente)

O resultado da experiência de Joule com as pás e o corpo em queda não ficou claro. (Afonso)

Francisco elabora uma pergunta aparentemente simples, mas cuja resposta está no cerne da segunda lei da termodinâmica e do conceito de entropia:

Por que o calor é transferido de um corpo com mais calor para um de menos calor e não o contrário? (Francisco)

O funcionamento das máquinas térmicas também gerou curiosidades e dúvidas: 
Como foi a primeira máquina a vapor realmente eficiente de James Watt? (Washington)

Como diminuir a dissipação de calor em qualquer máquina? (Julia)

Possivelmente, um dos fatores para a grande incidência de dúvidas sobre a teoria cinética é o fato desse tópico não ser, geralmente, tratado em aulas de Física no Ensino Médio, configurando-se como algo completamente novo para muitos estudantes no início do ensino superior:

Como a teoria dos gases está relacionada ao conceito de calor? (Ângela)

Como se obteve a velocidade média das moléculas? (Joana)

Qual a relação entre as colisões das moléculas e a formação do calor? (Tatiane)

As moléculas realmente vibram sozinhas ao receber energia em forma de calor? Por quê? (Hélio)

Nelson tenta compreender o comportamento das moléculas em cada fase, mas esbarra em uma concepção equivocada acerca da estrutura da matéria.

Tenho dúvidas em relação ao calor em sólidos e principalmente em líquidos devido a essa questão dos choques, porque entendo que nos líquidos não há espaço e a matéria está organizada de forma a não propiciar espaços vazios e está bem compacta (Nelson).

Os antigos conceitos de calórico e flogisto suscitaram dúvidas:

Antes de Sthal, o calor tinha alguma definição? (Valdir)

Não entendi a diferença entre flogisto e calórico. (Josias)

Por que muitos conceitos e fórmulas utilizadas até hoje são aceitas mesmo sendo desenvolvidas com o conceito de calórico? (Sérgio)

Fernanda coloca uma questão epistemológica interessante, procurando entender os métodos empregados no desenvolvimento das teorias científicas:

A produção de novas teorias e a evolução do conhecimento deve-se inicialmente ser baseada em um fato já existente ou pode apenas ser baseada na intuição? Com a produção da primeira teoria de um dado fato, as outras teorias relacionadas a esse fato terão sempre que ser baseadas nessa primeira teoria? (Fernanda)

Os relatos analisados revelam um efetivo trabalho com o texto por parte dos estudantes, que apontaram dúvidas sobre os mais variados aspectos, propondo questões relevantes e interessantes sobre a ciência e sua produção. Sem tal 
oportunidade de expressão, provavelmente muitos desses questionamentos não seriam manifestados. O professor pôde, então, utilizá-los durante a preparação das aulas seguintes da disciplina, a fim de respondê-los e discuti-los, o que certamente enriqueceu o curso. A leitura do texto suscitou dúvidas sobre conceitos que, claramente, demandam a atuação mediadora do docente, indo além do próprio texto. Assis e Carvalho (2008) também destacam a importância, para as relações de ensino e aprendizagem, de o professor mediar o conhecimento abordado pelo texto. É claro que não se deve esperar que o texto de divulgação, ou outro de qualquer natureza, por si só, garanta a aprendizagem, mas quanto maior a variedade de elementos por ele trazidos, maiores são as possibilidades de mediação e articulações nas aulas. Nesse aspecto, textos de divulgação podem ser complementares aos livros didáticos.

\section{c. Percepções acerca da evolução do conhecimento científico}

A proposição da terceira questão justifica-se pelo fato de o texto abordar parte do desenvolvimento histórico da termodinâmica, permitindo interpretações sobre como é possível ocorrer uma evolução de conceitos em Física e a produção de novos conhecimentos. Pelos exemplos das construções da teoria cinética e da termodinâmica, pode-se caracterizar o desenvolvimento científico e tecnológico como um processo dinâmico que demanda contribuições de diversas pessoas, tempo, envolve experiências práticas e cálculos, se insere no contexto social, econômico e cultural do lugar e da época, e gera conflitos entre ideias e concepções teóricas, que podem conduzir a mudanças de paradigmas.

Flávio destaca o embate entre diferentes ideias como estímulo para o avanço da ciência:

A evolução do conhecimento científico acontece por meio de descobertas e experimentos de cientistas que combatem ou reforçam o que foi descoberto por seus predecessores. Isso mostra que é o debate (o confrontamento de diferentes teorias com diferentes visões) que estimula a produção de novos conceitos na ciência. (Flávio)

Rogério coloca que a necessidade tecnológica é um componente que impulsiona o desenvolvimento científico, citando a relação entre os adventos da termodinâmica e da revolução industrial:

É possível observar no texto que o desenvolvimento da ciência está intimamente ligado à necessidade de desenvolvimento do homem. O surgimento da Termodinâmica é fruto da busca do desenvolvimento de máquinas eficientes na época da Revolução Industrial. Não que a necessidade tecnológica seja a única causa do desenvolvimento científico, mas não podemos negar que essa necessidade tecnológica dá impulso à produção do conhecimento científico. (Rogério)

Por sua vez, Sérgio atenta para a vinculação entre o desenvolvimento científico e tecnológico com interesses econômicos: 
[...] Com o advento da Revolução Industrial, a produção de conhecimento científico ficou atrelada aos aspectos econômicos de uma determinada região. Hoje, boa parte da produção de conhecimento científico está intimamente ligada à economia de determinado país ou grupo com forte poder econômico. (Sérgio)

\section{Afonso destaca o papel da experimentação na aceitação ou refutação de} uma teoria:

A partir dos conhecimentos já adquiridos até hoje, cria-se novas teses aprimorando ou contradizendo os conceitos atuais, assim partindo para comprovação experimental que determinará a aceitação ou não desta nova tese. Com o tempo, surgirão outras teses que derrubarão as mais recentes, criando-se, assim, um ciclo que garante a evolução e imortalidade da ciência. (Afonso)

Joana coloca que a produção de novos conceitos não é possível sem o estudo minucioso e crítico do que seria o estado da arte em determinada área:

Eu acredito que a produção de novos conceitos e a evolução do conhecimento científico deve-se ao estudo profundo do que já foi produzido pela ciência. Thompson, de alguma maneira, estudou, obteve conhecimento sobre a teoria do calórico para contrariá-la. Boltzmann estudou os resultados de Mawell para escrever sua obra. (Joana)

Talia acrescenta a necessidade de aceitação de uma nova ideia por parte da comunidade científica, além do papel da linguagem matemática, provavelmente quando pensa no caso da Física. Nota-se uma visão aparentemente indutivista da construção da ciência, quando fala em "repetições do fenômeno":

[...] Para que um pesquisador obtenha respostas coerentes sobre um fenômeno estudado, é necessário que ele repita o mesmo fenômeno inúmeras vezes, de forma diferenciada, a fim de comprovar que o que ocorre é de forma generalizada; que se atribua, se possível, valores matemáticos e cálculos que deem maior certeza e precisão na formulação de sua teoria e, finalmente, que essa ideia seja aceita na comunidade científica, onde ela será implementada com outros conhecimentos e descobertas ou simplesmente desmentida com o passar do tempo. (Talia)

Vicente exibe uma visão mística, que confere um atributo sobre-humano ou profético ao cientista idealizado, quando se refere à "intervenção divina":

A produção de novos conceitos se dá ao longo de experimentos, luta contra paradigmas e intervenção divina. (Vicente)

Tais respostas mostram aspectos que permeiam o imaginário dos alunos sobre a evolução da ciência, influenciado não somente pela leitura do texto, mas pela "bagagem" de concepções que historicamente desenvolveram, conforme ressalta a AD. Nota-se que "inspiração, motivação, necessidade, curiosidade" e até mesmo 
"intervenção divina" são elementos presentes no imaginário de alguns estudantes. Esses relatos revelam, não obstante os equívocos existentes, a pertinência de se buscar estratégias para abordar a complexa questão da construção do conhecimento científico, importante quando se almeja uma formação culturalmente mais rica. $\mathrm{O}$ texto de divulgação e a atividade realizada se prestaram a tal fim.

\section{d. Retificações e novas colocações: as formas de repetição}

Com relação à quarta e última questão, apenas 8 alunos escreveram que não acrescentariam ou modificariam nada em suas explicações sobre o conceito de calor. Intencionando estimular avanços nas concepções dos estudantes, sem esperar, entretanto, que a leitura do texto conduzisse à formação de concepções rigorosamente científicas sobre os temas abordados, essa questão permitiu observar um efetivo trabalho com o texto na maioria dos escritos analisados. Há indícios de que a leitura do texto de divulgação remeteu a uma reflexão para alguns aspectos sobre o tema calor, pois elementos nele contidos estiveram presentes nas respostas dos alunos.

No âmbito da AD, certos relatos revelam a ocorrência de deslizamentos a partir da leitura, uma desestabilização nas concepções iniciais dos estudantes e a produção de novos sentidos, em discursos que evidenciam avanços rumo a concepções um pouco mais elaboradas sobre o tema, ainda que alguns sentidos interditados estejam presentes em determinadas respostas. Isso porque não se espera que somente a leitura do texto conduza todos os alunos à elaboração do conceito de calor de forma rigorosamente científica, pois, conforme destacam Silva, Laburú e Nardi (2008), tal conceito é sutil e, mesmo na literatura especializada, observam-se algumas ambiguidades nos modos de defini-lo.

As transcrições seguintes de José, João e Adriana, exemplificam tais observações, para as quais a natureza da pergunta contribuiu para a ocorrência do que Orlandi (2007) classificou como repetição histórica nos discursos produzidos. Não são meras cópias de partes do texto, procurando dar uma resposta correta, mas indícios da ocorrência de reflexões sobre o que a leitura do texto propiciou em termos de conhecimentos retificados, indo além dos dizeres explícitos no texto. Por exemplo, José retifica sua concepção sobre o calor, explicitando a diferença entre calor e temperatura e associando esta última à energia interna do corpo. Em sua resposta à primeira questão, José escreve que "calor é uma sensação térmica ocasionada pela agitação das partículas”. Na quarta questão, responde que:

Calor não é uma sensação térmica. Calor é a energia transferida entre dois corpos que estão a temperaturas diferentes. Todo corpo tem uma certa quantidade de energia interna que está relacionada ao movimento aleatório de seus átomos ou moléculas e esta energia é diretamente proporcional à temperatura do objeto. (José)

Parcela considerável das colocações dos estudantes incidiu sobre a teoria cinética, que descreve as grandezas termodinâmicas do ponto de vista molecular. É o caso de João, que na resposta à questão 1 enfatizou as conversões de energia e para a quarta questão acrescentou outros aspectos: 
Acrescentaria apenas sobre a energia cinética das moléculas, que são a principal fonte de calor existente, onde quanto mais colisões ocorrem entre as moléculas de um composto, maior a quantidade de calor gerado e maior sua temperatura. (João)

Adriana parece abandonar a noção de que o calor é algum tipo de elemento contido em um sistema e que seria responsável pela diferença de temperatura entre o sistema e sua vizinhança, relacionando-o a um fluxo de energia que ocorre por causa da diferença de temperatura entre ambos. $\mathrm{Na}$ sua resposta à primeira questão, Adriana afirma que "o calor é uma energia que pode ser transferida de um sistema para outro, fazendo com que a temperatura do sistema varie”. Em resposta à quarta questão, afirma que:

O calor é a energia transferida devido à diferença de temperatura entre um sistema e sua vizinhança e não a causa da diferença de temperatura. (Adriana)

Por sua vez, Rosa destaca a produção de força motriz a partir do calor, fundamental para a consolidação da Revolução Industrial e que contribuiu para modificar as relações de poder econômico e político na sociedade, bem como a importância do calor irradiado pelo Sol para a manutenção da vida.

Ficou provado que o calor pode ser gerado com o atrito de duas superfícies de mesma temperatura, ou através do movimento (energia cinética). Não tratei de um aspecto muito relevante em relação ao calor que é o fato da produção de energia, da máquina a vapor e dos impactos econômicos causados pelo calor na Revolução Industrial. E acrescentaria um comentário sobre a importância do Sol e seu calor em nossa vida no planeta Terra. (Rosa)

Eu acrescentaria utilizando conceitos técnicos-científicos, como o do método estatístico na descrição do movimento das moléculas de um gás e que tal método determina as propriedades macroscópicas dos gases. (Bruno)

Rosa e Bruno constroem frases usando termos contidos no texto, sem derivações, o que nos permite classificar suas respostas, no âmbito da AD, como exemplos de repetição formal. Esse tipo de repetição foi a que apresentou maior incidência nas respostas.

Afonso e Roberta copiam literalmente trechos do texto, caracterizando o que a $\mathrm{AD}$ denomina repetição empírica:

[...] embora seja fácil converter trabalho mecânico em calor, o contrário é muito mais difícil. Apenas uma fração do calor gerado num sistema é útil, no sentido de ser capaz de ser convertido em trabalho mecânico organizado. (Afonso)

Combustão é o resultado da combinação química entre o material combustível e o oxigênio [...]. (Roberta) 
Nessas situações, ainda que as respostas apresentadas estejam corretas, acrescentando informações ao que foi respondido na primeira questão, o fato de serem meras cópias não nos permite avaliar se novos sentidos foram efetivamente construídos pelos estudantes que assim procederam.

Os diferentes aspectos destacados pelos estudantes podem estar relacionados com partes do texto que mais atraíram ou despertaram interesses pessoais na leitura, além da preocupação em corrigir e completar a resposta dada anteriormente. Tal afirmação é feita baseando-se no fato de que a maioria dos alunos acrescentou às suas respostas somente um determinado tópico que era abordado no texto.

Quanto aos eventuais comentários sobre a atividade, apesar de poucos estudantes manifestarem suas opiniões, Carlos observa que seria interessante realizar esse tipo de leitura no Ensino Médio.

Acredito que atividades como essa devem ser incentivadas não só no ensino superior, como também no Ensino Médio, fazendo com que os ingressantes ao curso de graduação tenham um senso crítico mais apurado. (Carlos)

Alexia afirma que o texto foi uma leitura agradável e espera que seja útil para o entendimento da disciplina, ajudando a dar sentido às equações.

O texto é fácil de ser compreendido o que torna a leitura mais agradável. Além disso, conhecer a história da termodinâmica é importante para compreendermos a disciplina, fenômenos térmicos e a utilização das fórmulas propostas. (Alexia)

O problema da compreensão da linguagem matemática é recorrente no ensino de Física. O texto de divulgação pode ser um recurso para auxiliar a constituição de sentidos para os conceitos, com essa compreensão conceitual podendo se refletir em um melhor entendimento do significado dos símbolos matemáticos que representam as grandezas físicas, bem como suas relações através das fórmulas.

\section{CONSIDERACְÕES FINAIS}

O texto escrito continua sendo o principal instrumento usado no ambiente escolar e acreditamos que a utilidade atribuída à sua capacidade em auxiliar o aprendizado não será desvalorizada. Assim, é relevante refletirmos sobre como trabalhar com os diferentes tipos de texto e as implicações de tais práticas, uma vez que um texto de divulgação científica não é lido da mesma forma que um livro didático ou um artigo científico, por estarem envolvidas condições diferentes para produção de sentidos nesses distintos gêneros textuais.

Não pretendemos sugerir que nas disciplinas introdutórias de Física, nos cursos superiores, se abandone a adoção dos livros didáticos e a prática de resolução 
de listas de exercícios. Textos de divulgação, destinados basicamente a um público leigo no assunto, usualmente não trazem aspectos formais dos temas abordados, aspectos estes que são imperativos para a formação profissional do estudante em sua área. Desse modo, o uso da divulgação científica precisa ser planejado, considerando-se os objetivos do ensino, os conteúdos a serem cumpridos e a carga horária da disciplina.

Contudo, os manuais didáticos tradicionalmente usados nas disciplinas de Física básica, em nossas universidades, pouco destacam, por exemplo, aspectos da história da ciência e suas implicações sociais, e por vezes apresentam os conceitos de modo sucinto, sem uma discussão mais ampla sobre seus significados. Esses enfoques, em geral, os textos de divulgação procuram trazer. Por isso, uma articulação planejada entre a prática habitual e a perspectiva de outras mediações, como as propiciadas pela leitura de textos de divulgação e de outros gêneros literários, tende a contribuir positivamente para a formação do estudante, em um contexto mais amplo de objetivos para o ensino de ciências. Os resultados obtidos nesta investigação, bem como os de alguns autores aqui citados, apontam para a possibilidade de que a mediação prévia com textos de divulgação científica possa auxiliar a abordagem posterior dos conteúdos.

A proposta de trabalho apresentou um caráter motivacional, verificado pela participação mais ativa dos alunos nas aulas subsequentes. O professor retomou as dúvidas e comentários dos estudantes conforme desenvolvia os tópicos da ementa. Ocorreram interações entre o docente e os estudantes, através de mediações dialógicas baseadas no que eles haviam lido no texto de divulgação e respondido no questionário, no que estava sendo exposto nas aulas e no conteúdo do livro didático. Tais interações provavelmente não aconteceriam sem a oportunidade propiciada pela atividade desenvolvida. Os deslizamentos nos discursos dos estudantes, constatados ao compararmos as respostas dadas à primeira e à quarta questões, revelam avanços em suas concepções sobre o conceito de calor, ainda que alguns sentidos equivocados permaneçam. Noções acerca da evolução do conhecimento científico foram manifestadas e obtivemos indícios de que o texto lido integrou-se, ao menos no decorrer da disciplina, aos elementos constitutivos de seus discursos.

\section{REFERÊNCIAS BIBLIOGRÁFICAS}

ALMEIDA, M. J. P. M. O texto escrito na educação em física: enfoque na divulgação científica. In: SILVA, H. C. (Ed.). Linguagens, leituras e ensino da ciência. São Paulo: Mercado das Letras, 1998, p. 53-68.

ALMEIDA, M. J. P. M. Discursos da Ciência e da Escola: Ideologia e Leituras Possíveis. Campinas: Mercado das letras, 2004.

ALMEIDA, M. J. P. M.; RICON, A. E. Divulgação científica e texto literário: uma perspectiva cultural em aulas de física. Caderno Catarinense de Ensino de Física, Florianópolis, v.10, n.1, p.7-13, 1993.

ASSIS, A.; CARVALHO, F. L. C. A postura do professor em atividades envolvendo a leitura de textos paradidáticos. Revista Brasileira de Pesquisa em Educação em Ciências, São Paulo, v.8, n.3, 2008.

BACHELARD, G. A formação do espírito cientifico. Trad. Estela dos Santos Abreu. Rio de Janeiro: Contraponto, 1996. 
DIAS, R. H. A.; ALMEIDA, M. J. P. M. Especificidades do jornalismo científico na leitura de textos de divulgação científica por estudantes de licenciatura em física. Revista Brasileira de Ensino de Física, São Paulo, v.31, n.4, 2009.

GLEISER, M. A Dança do Universo. Cap.6, p.204-218. São Paulo: Companhia das letras, 1997.

HALLIDAY, D; RESNICK, R.; WALKER, J. Fundamentos de Física, v. 2, 7ª ed. Rio de Janeiro: LTC, 2006.

LOPES, A. R. C. Contribuições de Gaston Bachelard ao ensino de ciências. Enseñanza de las Ciencias, Vigo, Espanha, v.11, n.3, p.324-330, 1993.

MARTINS, I.; NASCIMENTO, T. G.; ABREU, T. B. Clonagem na sala de aula: um exemplo do uso didático de um texto de divulgação científica. Investigações em Ensino de Ciências, Porto Alegre, v.9, n.1, p.95-111, 2004.

MARTINS, R. A. Como distorcer a física: considerações sobre um exemplo de divulgação científica 1 - física clássica. Caderno Catarinense de Ensino de Física, Florianópolis, v.15, n.3, p. 243-264, 1998.

NASCIMENTO, T. G. Contribuições da análise do discurso e da epistemologia de Fleck para a compreensão da divulgação científica e sua introdução em aulas de ciências. Ensaio - Pesquisa em Educação em Ciências, Belo Horizonte, v.7, n.2, p.1-18, 2005.

NASCIMENTO, T. G.; CASSIANI, S. Leituras de Divulgação Científica por Licenciandos de Ciências Biológicas. Revista Electrónica de Enseñanz̧a de las Ciencias, Vigo, v.8, n.3, p.745-769, 2009. Disponível em <http://www.saum.uvigo.es/reec>. Acesso em: 20 out. 2011.

ORLANDI, E. P. Discurso, imaginário social e conhecimento. Em Aberto, Brasília, ano 14, n.61, 1994.

ORLANDI, E. P. Paráfrase e Polissemia: a fluidez nos limites do simbólico. Revista Universitária Audiovisual, Campinas, n.4, p. 9-19, 1998.

ORLANDI, E. P. Interpretação: autoria, leitura e efeitos do trabalho simbólico. 5ed. Campinas: Pontes Editores, 2007.

PINTO, G. A. Divulgação científica como literatura e o ensino de ciências. Orientador: Maurício Pietrocola Pinto de Oliveira. 2007. Tese (Doutorado em Educação) - Faculdade de Educação, Universidade de São Paulo, São Paulo, 2007

SALÉM, S.; KAWAMURA, M. R. D. O texto de divulgação e o texto didático: conhecimentos diferentes? In: ENCONTRO DE PESQUISADORES EM ENSINO DE FÍSICA, 5., 1996. Belo Horizonte. Atas... Belo Horizonte: Sociedade Brasileira de Física, 1996.

SILVA, J. A.; KAWAMURA, M. R. D. A natureza da luz: uma atividade com textos de divulgação científica em sala de aula. Caderno Catarinense de Ensino de Física, Florianópolis, v.18, n.3, p.316-339, 2001.

SILVA, O. H. M.; LABURÚ, C. E.; NARDI, R. Reflexões para subsidiar discussões sobre o conceito de calor na sala de aula. Caderno Brasileiro de Ensino de Física, Florianópolis, v.25, n.3, p.383-396, 2008.

SMITH, F. Leitura Significativa. 3a ed. Porto Alegre, RS: Artmed, 1999.

STRACK, R.; LOGUÉRCIO, R.; DEL PINO, J. C. Percepções de professores de ensino superior sobre a literatura de divulgação científica. Ciência \& Educação, Bauru, v.15, n.2, p.425-442, 2009.

ZANON, D. A. V.; ALMEIDA M. J. P. M.; QUEIROZ, S. L. Contribuições da leitura de um texto de Bruno Latour e Steve Woolgar para a formação de estudantes em um curso superior de Química. Revista Electrónica de Enseñanza de las Ciências, Vigo, v.6, n.1, p.56-69. Disponível em: < http:/ /www. saum.uvigo.es/reec>. Acesso em: 20 out. 2011.

ZANETIC, J. Física e cultura. Ciência e Cultura, São Paulo, v.57, n.3, p.21-24, 2005.

Data do Recebimento: 10/08/2012

Data de Aprovação: 27/12/2012

Data da Versão Final: 29/01/2013 